\title{
Corrigendum: Protective effects of intermittent hypoxia on brain and memory in a mouse model of apnea of prematurity
}

\author{
Myriam Bouslama ${ }^{1,2+}$, Homa Adle-Biassette ${ }^{1,2,3+}$, Nelina Ramanantsoa ${ }^{1,2}$, \\ Thomas Bourgeois 1,2, Bieke Bollen 1,2,4, Olivier Brissaud 1, 2, 5, Boris Matrot 1,2, \\ Pierre Gressens ${ }^{1,2 \ddagger}$ and Jorge Gallego ${ }^{1,2 * \neq}$ \\ ${ }^{1}$ Inserm, U1141, Robert Debré Hospital, Paris, France, ${ }^{2}$ Paris Diderot-Paris 7 University, Paris, France, ${ }^{3}$ Department of \\ Pathology, Lariboisière Hospital, AP-HP, Paris, France, ${ }^{4}$ Laboratory of Biological Psychology, University of Leuven, Leuven, \\ Belgium, ${ }^{5}$ Neonatal Intensive Care Unit, Bordeaux University Hospital, Bordeaux, France
}

Keywords: sleep disordered breathing, neurogenesis, brain injury, cognitive dysfunction, control of breathing

\section{OPEN ACCESS}

Edited and reviewed by: Keith Russell Brunt,

Dalhousie University, Canada

*Correspondence: Jorge Gallego jorge.gallego@inserm.fr

${ }^{\dagger}$ These authors have contributed equally to this work

${ }^{\ddagger}$ Jointly supervised this work.

Specialty section:

This article was submitted to Respiratory Physiology, a section of the journal Frontiers in Physiology

Received: 17 February 2016 Accepted: 04 March 2016 Published: 22 March 2016

Citation:

Bouslama M, Adle-Biassette $H$, Ramanantsoa N, Bourgeois $T$, Bollen B, Brissaud O, Matrot B, Gressens P and Gallego J (2016) Corrigendum: Protective effects of intermittent hypoxia on brain and memory in a mouse model of apnea of prematurity. Front. Physiol. 7:105.

doi: 10.3389/fphys.2016.00105

\section{A corrigendum on}

Protective effects of intermittent hypoxia on brain and memory in a mouse model of apnea of prematurity

by Bouslama, M., Adle-Biassette, H., Ramanantsoa, N., Bourgeois, T., Bollen, B., Brissaud, O., et al. (2015). Front. Physiol. 6:313. doi: 10.3389/fphys.2015.00313

Due to an error in the proofs missed by the authors, the name of the author Homa Adle-Biassette was reported incorrectly as Homa Adla-Biassette. Also the citation was Adla-Biassette $\mathrm{H}$ instead of Adle-Biassette $\mathrm{H}$.

The affiliation for Dr. Adle-Biassette was incomplete and should be Department of Pathology, Lariboisière Hospital, AP-HP, Paris, France.

The authors apologize for these mistakes. The errors do not affect the scientific results of the article in any way.

The original article has been updated.

\section{AUTHOR CONTRIBUTIONS}

All authors listed, have made substantial, direct and intellectual contribution to the work, and approved it for publication.

Conflict of Interest Statement: The authors declare that the research was conducted in the absence of any commercial or financial relationships that could be construed as a potential conflict of interest.

Copyright $\odot 2016$ Bouslama, Adle-Biassette, Ramanantsoa, Bourgeois, Bollen, Brissaud, Matrot, Gressens and Gallego. This is an open-access article distributed under the terms of the Creative Commons Attribution License (CC BY). The use, distribution or reproduction in other forums is permitted, provided the original author(s) or licensor are credited and that the original publication in this journal is cited, in accordance with accepted academic practice. No use, distribution or reproduction is permitted which does not comply with these terms. 